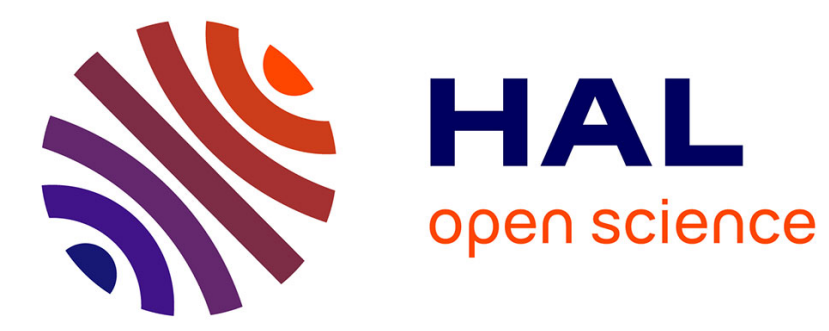

\title{
Low energy interband transitions in aluminium
}

\author{
A. Humbert, J.M. Debever, J. Hanus, C. Jourdan
}

\section{To cite this version:}

A. Humbert, J.M. Debever, J. Hanus, C. Jourdan. Low energy interband transitions in aluminium. Journal de Physique Lettres, 1977, 38 (24), pp.479-481. 10.1051/jphyslet:019770038024047900 . jpa00231425

\section{HAL Id: jpa-00231425 https://hal.science/jpa-00231425}

Submitted on 1 Jan 1977

HAL is a multi-disciplinary open access archive for the deposit and dissemination of scientific research documents, whether they are published or not. The documents may come from teaching and research institutions in France or abroad, or from public or private research centers.
L'archive ouverte pluridisciplinaire HAL, est destinée au dépôt et à la diffusion de documents scientifiques de niveau recherche, publiés ou non, émanant des établissements d'enseignement et de recherche français ou étrangers, des laboratoires publics ou privés. 


\title{
LE JOURNAL DE PHYSIQUE-LETTRES
}

Classification

Physics Abstracts

$71.25 \mathrm{P}-78.20 \mathrm{~N}$

\section{LOW ENERGY INTERBAND TRANSITIONS IN ALUMINIUM}

\author{
A. HUMBERT, J. M. DEBEVER, J. HANUS \\ Groupe de Physique des Etats Condensés (*), UER Luminy \\ 70, route Léon Lachamp, 13288 Marseille Cedex 2, France \\ and \\ C. JOURDAN \\ Centre de Recherche des Mécanismes de la Croissance Cristalline (**), \\ St-Jérôme, 13397 Marseille Cedex 4, France
}

(Reçu le 26 septembre 1977, accepté le 21 novembre 1977)

\begin{abstract}
Résumé. - Les spectres de thermoréflectance de monocristaux d'aluminium présentent des structures à 0,5 et $1,5 \mathrm{eV}$. L'analyse de ces spectres donne la variation avec la température des coefficients $V(111)$ et $V(200)$ du speudopotentiel. Le modèle à deux bandes parallèles est inadéquat pour expliquer complètement les spectres observés. Une étude de la variation avec l'énergie des coefficients du pseudopotentiel semble possible.
\end{abstract}

Abstract. - Thermoreflectance spectra of single crystals of aluminium show very clearly transitions at 0.5 and $1.5 \mathrm{eV}$. Analysis of the spectra yields the temperature variation of the pseudo-potential coefficients $V_{111}$ and $V_{200}$. Discrepancies between the data and the two parallel band model point to possible studies of the energy variation of these coefficients.

Aluminium is certainly the polyvalent metal whose optical properties have been most througly studied [1]. The spectrum is rather flat, dominated by a strong absorption peak near $1.5 \mathrm{eV}$ and a much weaker one around $0.5 \mathrm{eV}$. This last structure was observed only quite recently with a calorimetric technique by Bos and Lynch [2]. These two structures are qualitatively well described theoretically. In polyvalent metals, there are parallel bands where the Fermi surface cuts the Brillouin zone. Partly empty, partly occupied thoroughout a region of $k$ space, such parallel bands lead to sharp peaks in the conductivity at a photon energy of $2\left|V_{\mathrm{G}}\right|$, where $V_{\mathrm{G}}$ is the appropriate Fourier coefficient of the pseudo-potential [3-5]. Here we report on new thermoreflectance measurements which show clearly the two structures and give the variation between helium and room temperature of the pseudo-potential coefficients. Our experiments complement earlier data by Rosei and Lynch [6], they had observed the $2\left|V_{200}\right|$ transition at $1.5 \mathrm{eV}$ but failed to detect the $2\left|V_{111}\right|$ transition.

The samples were prepared from sheets $2 \mathrm{~mm}$ thick of $99.98 \%$ aluminium. The sheet was then unidirectionally rolled to $0.25 \mathrm{~mm}$. The temperature of the

(*) Equipe de recherche associée au C.N.R.S.

(**) Laboratoire propre du C.N.R.S. metal was then raised very slowly to $515^{\circ} \mathrm{C}$ and it was annealed at that temperature for 72 hours to secure a good recrystallization [7]. The aluminium was very slowly brought back to room temperature, and the samples were then electropolished to the desired thickness of about $0.1 \mathrm{~mm}$. The samples were in the form of large single crystals with perhaps $10^{7} \mathrm{~cm}^{-3}$ defects. The number of defects is drastically raised when the sample is clamped at the cold tip of a variable temperature cryostat. The surface of the sample is formed by a $10 \AA$ layer of amorphous $\mathrm{Al}_{2} \mathrm{O}_{3}$, and complexes of $\mathrm{Cl}$ and $\mathrm{P}$ [7].

The temperature of the sample is modulated by electron bombardement [8], we can feed up to one watt of modulating power. In this technique, the sample is not strained against a substrate and this partly explains why we observed a large signal at $0.5 \mathrm{eV}$, besides the fact we have good sized monocrystals.

Our data is seen in figure 1. With a good signal to noise ratio, the two peaks are clearly seen and we have followed their temperature evolution from about helium temperature to room temperature. As in ref. [6], there is no sign of any structure at $0.8,1.2$ and 1.45 as predicted and reported [9], neither do we see the fine structure on the $1.5 \mathrm{eV}$ transition recently reported [10]. Perhaps could we only mention the 


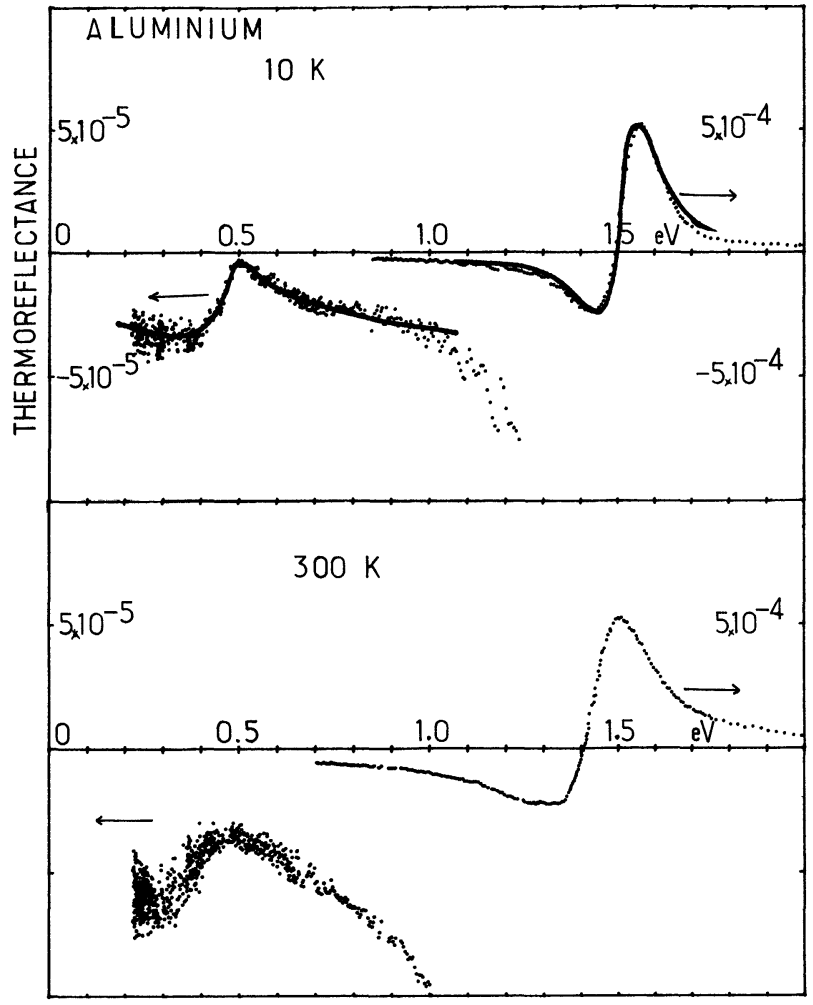

Fig. 1. - Thermoreflectance spectra of a $100 \mu$ single crystal sample of aluminium, at $10 \mathrm{~K}$ and $300 \mathrm{~K}$. The low energy data reads on the $5 \times 10^{-5}$ scale, the high energy ones on the $4 \times 10^{-4}$ scale. On the $10 \mathrm{~K}$ data is shown a typical fit with the parallel band model.

extra hump between 1.1 and $1.3 \mathrm{eV}$ at room temperature.

In these data, as opposed to Rosei and Lynch who also measured the thermotransmission, we have measured only the thermoreflectance and we have difficulties in quantitatively interpreting the data. It could be quite misleading to make a Kramers Krönig analysis of the $\Delta R / R$ spectrum since we have not measured the optical constants of our samples. The best thing to do was to see how far we could go with the parallel bands analysis. At any given temperature, the interband conductivity from transitions between parallel bands is given by Ashcroft and Strum [5] and depends on $\left|V_{G}\right|$ and $\tau_{G}$ a phenomenological interband relaxation time. With the Drude conductivity characterized by a relaxation time $\tau_{0}$ and the plasma frequency $\omega_{\mathrm{p}}$, we have therefore six parameters, each in principle temperature dependent. We have calculated the reflection coefficient from two sets of coefficients, hopefully at two slightly different temperatures and computed $\Delta R / R$. The starting values were taken from published data [9], in particular from Mathewson and Myers [11], the variations of the parameters were adjusted to optimize the fit. In no case was the agreement very good over the full experimental range. $\Delta V_{\mathrm{G}}$ is felt on the low energy side of the transition while $\Delta \tau_{\mathrm{G}}$ gives comparable amplitudes on both side of the transition but the rapid return to zero about $1.7 \mathrm{eV}$ cannot be obtained. The two structures can be adjusted more or less independently. The non zero averaged value of $\Delta R / R$ is given by $\Delta \tau_{0} / \tau_{0}$.

Over a large domain of reasonable values for the parameters, whatever the chosen values for $\tau_{\mathbf{G}}$ and $\Delta \tau_{\mathrm{G}}$, the inflexion point between the maximum and the minimum occurs quite accuratly at $2\left|V_{G}\right|$ when the parallel bands model is used and thus, we have an accurate determination of these two parameters as given in table $I$ for 4,77 and $300 \mathrm{~K}$, the accuracy being much greater for $\left|V_{200}\right|$ than for $\left|V_{111}\right|$. This inaccuracy is reflected in the apparent insensitivity of $V_{111}$ at low temperatures. The pseudo-potential coefficients have a marked variation with temperature, they are products of i) a form factor which depends on temperature through the thermal expansion and the dielectric function and ii) a structure factor with a Debye-Waller temperature dependence. Mathewson and Myers [11] have analysed their data in these terms, and we give in table I the zero temperature values deduced from such a reduction of the data.

\section{TABLE I}

\begin{tabular}{rlll}
\multicolumn{1}{c}{$V_{111}(\mathrm{eV})$} & \multicolumn{1}{c}{$V_{200}(\mathrm{eV})$} & \\
$4 \mathrm{~K}$ & $0.225 \pm 0.005$ & $0.753 \pm 0.002$ & present data \\
& 0.243 & 0.764 & dHvA, ref. [12] \\
& 0.988 & 0.985 & correction factor, ref. [11] \\
$0 \mathrm{~K}$ & $0.228 \pm 0.005$ & $0.764 \pm 0.002$ & present corrected \\
$77 \mathrm{~K}$ & $0.225 \pm 0.003$ & $0.745 \pm 0.002$ & present \\
$120 \mathrm{~K}$ & 0.216 & 0.772 & ref. [6] \\
$300 \mathrm{~K}$ & $0.185 \pm 0.01$ & $0.715 \pm 0.002$ & present \\
& 0.190 & 0.738 & ref. [11] \\
& 0.22 & 0.76 & ref. [4] \\
& 0.944 & 0.932 & correction factor, ref. [11] \\
$0 \mathrm{~K}$ & $0.196 \pm 0.01$ & $0.767 \pm 0.002$ & present corrected
\end{tabular}

In the table, we also give other determinations of the $V_{111}$ and $V_{200}$. Mathewson and Myers [11] and Motulevitch [4] determine the parameters from fits to the conductivity data. Rosei and Lynch [6] with thermoderivative data have determinations from $\Delta \varepsilon_{2}$, but have also the difficulties mentioned here due to inaccurate absolute values of the optical constants, and having not actually observed the structure at $0.5 \mathrm{eV}$, they, and all the other workers, deduced the values of $V_{111}$ from data a little outside the sensitive range.

A significant comparison is made with the values of the parameters deduced by Ashcroft [12] in an analysis of the low temperature dHvA data. The agreement is very good for $V_{200}$ but our value for $V_{111}$ is quite smaller and perhaps it is a good indication of the inadequacy of our analysis.

There are two ways of improving the theoretical expression to compare to the data :

1) to consider more than two bands in the pseudopotential calculation. The difference as shown by 
Ashcroft are small and lead to the fine structure of Hunderi and Nilsson, which is not observed here;

2) departures from parallelism and energy dependent pseudo-potential coefficients. Sturm and Ashcroft [13] have studied these points and analysing the data from Mathewson and Myers [11] concluded that an analysis of the optical data could yield this energy dependence. The simple two band model used here fails chiefly in that it leads to too wide structures but our lack of absolute accuracy prevents further analysis. Perhaps the good agreement between the different values of $V_{200}$ is misleading and the main result is the definite discrepancy between the values of $V_{111}$ determined from analysis of the $\mathrm{dHvA}$ data and the optical data. If the energy dependence of $V_{111}$ is significant, the two values should differ as emphasized in ref. [13].

Our data show that optical measurements can not only provide estimates of pseudo-potential coefficients, but high precision data could yield information on their energy dependence provided absolute measurements of the optical constants are made in conjunction with differential measurements.

\section{References}

[1] For a review, see NiLsson, P. O., in Solid State Phys. (Edited by Ehrenreich, Seitz and Turnbull, Academic Press, New York and London) 29 (1974) 139.

[2] Bos, L. W. and LynCH, D. W., Phys. Rev. Lett. 25 (1970) 156.

[3] Harrison, W. A., Phys. Rev. 147 (1966) 467.

[4] Motulevich, G. P., Usp. Fiz. Nauk 97 (1969) 211 ; Sov. Phys. Usp. 12 (1969) 80.

[5] Ashcroft, N. W. and Sturm, K., Phys. Rev. B 3 (1971) 1898.

[6] Rosei, R. and Lynch, D. W., Phys. Rev. B 5 (1972) 3883.

[7] Gastaldi, J., Marzo, P. and Jourdan, C., J. Cryst. Growth 18 (1973) 77
[8] For a description of the technique : Dallaporta, H., Debever, J. M. and Hanus, J., J. Physique Lett. 37 (1976) L-139.

[9] Dresselhaus, G., Dresselhaus, M. S. and Beaglehole, D., in Proceedings of the Third Materials Research Symposium, Gaithersburg, Nat. Bur. Std 323 (1971) 33.

[10] Hunderi, O. and Nilsson, P. O., Solid State Commun. 19 (1976) 921.

[11] Mathewson, A. G. and Myers, H. P., J. Phys. F 2 (1972) 403

[12] Ashcroft, N. W., Philos. Mag. 8 (1963) 2055.

[13] Sturm, K. and Ashcroft, N. W., Phys. Rev. B 10 (1974) 1343. 